\title{
CORTE PENAL INTERNACIONAL: ¿UN OBSTÁCULO PARA LA PAZ EN COLOMBIA?*
}

\author{
INTERNATIONAL CRIMINAL COURT: AN \\ OBSTACLE FOR PEACE IN COLOMBIA?
}

TRIBUNAL PENAL INTERNACIONAL: UM OBSTÁCULO À PAZ NA COLÔMBIA?

\section{RESUMEN}

Con el proceso de paz adelantado en Colombia, se ha pretendido poner fin a una guerra insana que ha desangrado al país por más de 50 años. De este modo, se inicia haciendo un esbozo del acontecer del conflicto, desde su génesis hasta la actualidad, para posteriormente ilustrar los esfuerzos del Estado en lograr una negociación que beneficie a las partes.

Sin embargo, y pese a la buena fe y disposición del Estado Colombiano, no ha sido posible concertar una solución; aunado a esto, no han sido benéficas las consideraciones de algunos organismos internacionales, tal como la Corte Penal, la cual considera que al estar frente a casos de amnistía por los crímenes cometidos por las FARC, deberá intervenir para juzgar a estas personas por sus conductas de lesa humanidad, teniendo en cuenta, además, que Colombia aprobó los estatutos para la creación de dicha Corte.

* Artículo de reflexión.

a. Abogada, Universidad Libre de Colombia; especialista en Derecho Contractual y Tributario, Universidad Colegio Mayor de Nuestra Señora del Rosario; magíster en Derecho Penal y Criminología; catedrática, Universidad Colegio Mayor de Cundinamarca.

Luz Mary Rincón Romero ${ }^{a}$ luzmaryrincon@yahoo.es

Fecha de recepción: 23 de Mayo 2014 Fecha de revisión: 17 de Diciembre 2014 Fecha de aceptación: 22 de Diciembre 2014 


\section{PALABRAS CLAVES}

Conflicto, soberanía, derecho penal, derecho penal internacional, responsabilidad estatal, paz, derechos humanos.

\begin{abstract}
With the advance of the peace process in Colombia, we have tried to put an end to an insane war that has bled the country for over 50 years. Thus, this article starts with an outline of the events of the conflict, from its origins to the present day, and subsequently illustrate the nation's efforts to achieve a negotiation that benefits the parties.
\end{abstract}

However, despite the good faith and willingness of the Colombian Government it has not been possible to arrange a solution, coupled with this considerations of some international organizations such as the ICC have not been beneficial. This organization believes that it must intervene against cases of amnesty for crimes committed by the FARC, and be the ones to judge these people for their behavior against humanity, taking into account that Colombia has approved the statutes for the creation of the above mentioned Court.

\section{KEY WORDS}

Conflict, sovereignty, criminal law, international criminal law, state responsibility, peace, Human Rights.

\section{RESUMO}

Com o avanço do processo de paz na Colômbia, temos tentado parar uma guerra insana que sangra o país há mais de 50 anos. Desta forma, 0 artigo começa com um esboço dos acontecimentos do conflito, desde sua gênese até os dias atuais, para em seguida ilustrar os esforços do Estado para alcançar uma negociação que beneficie as partes.

No entanto e apesar da boa-fé e da vontade do Estado colombiano, não tem sido possível identificar uma solução. Somado a isso, não têm sido benéficas as considerações de organismos internacionais, como o Tribunal Penal Internacional, que considera que, ao estar perante casos de anistia por crimes cometidos pelas FARC, deverá intervir para julgar essas pessoas pelo seu comportamento contra a humanidade, levando em conta também que a Colômbia aprovou os estatutos para a criação do Tribunal.

\section{PALAVRAS-CHAVE}

Conflito, soberania, direito penal, direito penal internacional, responsabilidade do Estado, paz, direitos humanos.

\section{INTRODUCCIÓN}

La jurisdicción de la Corte Penal Internacional es complementaria a la de los Estados partes. Esto significa que cuando un Estado está juzgando o ha juzgado un caso, la CPI no puede entrar a conocer del mismo, a menos que se demuestre que, conforme a los principios del debido proceso, reconocidos por el Derecho internacional, dicho Estado no quiere, o no puede, llevar a cabo el juicio (art. 17 No. 1 (a), No. 2). El Estatuto de la Corte no considera expresamente las amnistías y los indultos como casos en las cuales un Estado no quiere, o no puede, juzgar internamente a quienes cometan los delitos relacionados en el artículo 5 del Estatuto. Sin embargo, sí existen razones para pensar que las amnistías no permiten que se conozca la verdad acerca de la comisión de ciertos crímenes e impiden que se responsabilice, aunque sea formalmente, a los culpables; las amnistías son contrarias a los principios del debido proceso reconocidos por el derecho internacional ${ }^{1}$.

El objeto jurídico de estas instituciones ha sido investigary condenar a los individuos responsables por violaciones de derechos humanos, en los casos en que los sistemas judiciales nacionales han sido ineficaces (así sea temporalmente). La condena de este tipo de delitos tiene, a su vez, un propósito político principal: prevenir que sucedan en el futuro. Si se tiene en cuenta que la función de condenar individuos es bastante sui géneris dentro del Derecho internacional y, de hecho,

1 Adicionalmente, debe tenerse en cuenta que el Proyecto de Estatuto hacía mención de las amnistías e indultos, tanto para decir que en tales casos el asunto era inadmisible, como para determinar que la Corte podía conocer de tales casos cuando la amnistía o el indulto excluyera la posibilidad de otorgarle al criminal una pena apropiada. Sin embargo, ninguna de las dos propuestas fue aceptada. Véase, Comité Preparatorio sobre el Establecimiento de una Corte Penal Internacional, "Proyecto de Estatuto..." arts. 11 [35] y 13 bis respectivamente,, correspondientes a los asuntos de admisibilidad (actual art. 17 del Estatuto). 
implica una extensión de sus alcances, el lector encontrará razones suficientes para considerar que la comparación de las diversas instituciones, no solamente es posible, sino que es útil, en particular, para mostrar la relación dinámica que hay entre la paz y la justicia. Es necesario estudiar las posibilidades que ha ofrecido históricamente esta relación para identificar soluciones a los problemas que puede presentar el proceso de paz en Colombia.

Así las cosas, es preciso cuestionarse sobre varios aspectos que, distinto al anhelo de un país sin guerra, deben considerarse objetivamente, tales como: ¿Puede el gobierno aceptar, por un lado, la obligación de entregar un criminal a la Corte Penal Internacional y, por el otro, declarar una amnistía en la cual dicho criminal está incluido? En casos como éste, en que parecen enfrentarse la necesidad de la paz y el imperativo de hacer justicia, ¿Cómo se deben ponderar cada uno de estos dos valores? ¿Son acaso, inexorablemente, mutuamente excluyentes? o ¿Debe Colombia ignorar todas estas circunstancias y considerar a la Corte como un obstáculo más para lograr sus fines?

\section{Historia de los tribunales penales internacionales y la búsqueda de la paz y la seguridad internacionales: Nuremberg, la paz de los victoriosos}

Los Tribunales de Nuremberg, creados por la Carta del Tribunal Internacional Militar, anexado al Acuerdo de Londres para el Enjuiciamiento y Castigo de los Principales Criminales de Guerra del Eje Europeo de 1945, fueron sui géneris en varios sentidos. En primera medida, fueron una imposición de una coalición victoriosa sobre los vencidos en la guerra, y no el producto de un acuerdo previo entre partes que se encontraban en un equilibrio de poder suficiente como para aceptar o rechazar su jurisdicción. En segunda medida, los jueces carecían en muchos casos de leyes preexistentes por las cuales juzgar a los criminales. Por ello, tuvieron que crear estatutos que contuvieran el derecho aplicable retroactivamente, es decir a crímenes ya cometidos, o apoyarse convenientemente en la existencia de un Derecho natural.

La precariedad de los fundamentos de la jurisdicción de los Tribunales de Nuremberg llevó a que, inicialmente, muchas personas cuestionaran la legitimidad de los fallos ${ }^{2}$. Sin embargo, la necesidad que tenían los Aliados y, en general, toda la comunidad internacional de que la historia de la Segunda Guerra no se repitiera, era suficiente motivo para que toda duda respecto de la legitimidad de los fallos se desvaneciera. Evitar una guerra semejante era un imperativo, y condenar a quienes la iniciaron parecía ser una estrategia eficaz.

Teniendo en mente que el objetivo era impedir el resurgimiento de una nueva guerra mundial, ¿cuál era el límite que debían respetar los magistrados para no volver a alimentar el resentimiento que el Tratado de Versalles ${ }^{3}$ había causado a los alemanes? La Carta de Londres (art. 6(a)) establecía categóricamente que todo soldado alemán que hubiese participado en una "guerra agresiva" debía ser condenado. A pesar de esto, a partir de 1948, varios tribunales, conducidos por estadounidenses, concluyeron que sólo se debía juzgar a aquellas personas que, encontrándose en altas esferas nacionales, estuvieran encargadas de establecer las directrices de la guerra. Sólo los principales criminales debían ser condenados. Debía permitirse a los alemanes reconstruir Alemania, y así garantizar el fin primordial de asegurar la paz.

La consolidación de la paz, como objetivo de los Tribunales de Nuremberg, también se hizo evidente en la formulación de los delitos, entre los cuales se encontraban los llamados "Crímenes Contra la Paz"4. Adicionalmente, los tribunales, de hecho, sólo asumieron jurisdicción sobre los crímenes de lesa humanidad, cuando éstos estaban relacionados con crímenes de guerra o con crímenes contra la paz, a pesar de que en la Carta de Londres no se establecía que fuera necesaria esta conexidad. Esto significa que los tribunales autolimitaron de facto su jurisdicción, para que sólo los crímenes sucedidos durante la

2 Dinstein, Yoram; International Criminal Law, en Israel Yearbook on Human Rights 5, p. 55, 1975, citado por Steiner, Henry y Alston, Philip (comps.); Human Rights in Context, Clarendon Press, Oxford, 1996, p. 1026.

3 En cumplimiento del Tratado de Versalles, los alemanes se vieron obligados a entregar a los aliados alrededor de novecientas personas acusadas de violar las leyes de la guerra. Véase Meron, Theodor; The Case for War Crimes Triáis in Yugoslavia, en Foreign Affairs 122, No. 3,1993, p. 123.

4 La denominación "Crímenes contra la Paz", aunque no fue incluida en los Tribunales para la ex Yugoslavia y Rwanda, aparece en otro instrumento, el "Proyecto de Código de Crímenes contra la Paz y la Seguridad de la Humanidad", presentado por la Comisión de Derecho Internacional en 1954, 1978,1982 y 1991. 
guerra fueran juzgados, negándose a conocer aquéllos cometidos contra los judíos antes de la guerra. Juzgar crímenes cometidos contra un grupo determinado, por fuera de la guerra, implicaba desviarse de lo que sus creadores consideraban que era la finalidad política primordial de los Tribunales: asegurar la paz.

\section{Rwanda y Yugoslavia, viejos mecanismos para enfrentar nuevos retos a la paz}

Los tribunales penales internacionales comisionados ad hoc para Rwanda y Yugoslavia fueron creados por el Consejo de Seguridad de las Naciones Unidas, órgano encargado principalmente del mantenimiento de la paz y seguridad internacionales (art. 24 de la Carta Constitutiva de la ONU). La Resolución, mediante la cual se crearon, fue dictada de conformidad con las facultades otorgadas a este órgano de la $\mathrm{ONU}$ en el capítulo VII de su Carta constitutiva, que establece las acciones que puede tomar, en caso de que haya amenazas y ataques contra la paz internacional, o actos de agresión ${ }^{5}$.

Las dudas que suscitó, en un primer momento, la creación de estos tribunales ad hoc por parte del Consejo de Seguridad, estaban fundamentadas sobre dos cuestionamientos principales: El primero, que el capítulo VII de la Carta de la ONU, no faculta expresamente al Consejo de Seguridad para crear tribunales; el segundo, que la creación de un tribunal penal internacional no es una medida encaminada directamente a restablecer o mantener la paz de manera inmediata.

La primera de las objeciones es fácilmente controvertible, si se considera que el Consejo de Seguridad puede autorizar el uso de la fuerza para asegurar la paz. ¿Qué le impide, entonces, a un órgano político que tiene cierta discrecionalidad en sus funciones, tomar una medida menos radical para lograr su objetivo, mediante la creación de un tribunal?

5 El Tribunal Penal Internacional para la ex Yugoslavia fue creado por las Resoluciones 808 del 22 de febrero de 1993 y 827 del 25 de mayo de 1993, con sede en La Haya, Holanda. El Tribunal para Rwanda fue creado por la Resolución 955 de 1994, con sede en Arusha, Tanzania, y comparte con el de Yugoslavia la Sala de Apelaciones y el Fiscal. Sus Estatutos son prácticamente idénticos aun cuando el de Rwanda, por tratarse de un conflicto de naturaleza primordialmente interna, utiliza fuentes de ley distintas al de Yugoslavia.
La segunda de las objeciones, en cambio, está mejor fundamentada jurídica y políticamente, pues la creación del tribunal podía llegar a ser ineficaz o incluso generar aún más violencia. Sin embargo, no se puede olvidar que la creación del Tribunal en Yugoslavia no era la primera medida de la que hacía uso el Consejo de Seguridad, $\mathrm{y}$ que ninguna de las anteriores medidas parecía adecuada para controlar, por sí sola, las dimensiones del conflicto. Por lo tanto, este organismo resolvió seguir la recomendación ${ }^{6}$ de una Comisión de Expertos y del Secretario General de la ONU: dictar una Resolución que, con base en el capítulo VII, creara el Tribunal.

Aunque dentro de las motivaciones de las resoluciones que crearon el Tribunal para la ex Yugoslavia, está explícita la violación de los derechos humanos, es más importante que tales violaciones constituyen, según las mismas resoluciones, una amenaza a la paz y seguridad internacionales; en tal medida, se justifica la intervención del Consejo de Seguridad para crear un tribunal ad hoc. Según se puede ver en su desarrollo, este segundo motivo ha condicionado, en algunos casos importantes, la capacidad real del Tribunal de cumplir su función de juzgar y condenar a los criminales.

Tales son los casos de los procesos contra Radovan Karadzic y el general Ratko Mladic, tal vez los dos principales criminales de guerra serbobosnia. Los gobiernos estadounidense y francés trataron de arrestarlos en varias ocasiones, para someterlos a juicio ante el Tribunal, aunque los motivos para hacerlo eran eminentemente políticos. Estos países consideraron que los dos criminales ponían en peligro el Acuerdo de Dayton, del cual ellos habían sido garantes. Sin embargo, una vez analizada la situación, visto que una eventual operación para llevar a cabo el arresto, implicaría un recrudecimiento del conflicto y bajas de parte de las tropas internacionales en la ex Yugoslavia, el presidente estadounidense Bill Clinton, el primer ministro británico Tony Blair y el canciller alemán Hel-mut Kohl, decidieron no llevar a cabo la iniciativa de arresto planteada por Jacques Chirac. Los casos Karadzic y Mladic son sólo dos de tantos ejemplos de las limitaciones políticas para llevar

6 Presidida por M. Cherif Bassiouni, la Comisión entregó la recomendación de crear una corte ad hoc en su primer informe, en febrero de 1993. 
hasta sus últimas consecuencias la función del Tribunal de juzgar a los principales criminales de guerra. De hecho, según la investigación realizada por Thomas Sancton y Gilíes Delafon, "sólo unos 30 de los 70 individuos acusados han sido llevados ante el Tribunal, y la mayor parte de ellos, se ha entregado voluntariamente". ${ }^{7}$

\section{Antecedentes de la Corte Penal Internacional}

La Corte Penal Internacional es un proyecto que fue sugerido desde hace más de 75 años. Se habló de él después de la Primera Guerra Mundial, y fue revivido después de la Segunda Guerra. En 1947, la Asamblea General de la ONU encargó a la Comisión de Derecho Internacional (CDl) la elaboración de un proyecto de "Código de Crímenes contra la Humanidad". El siguiente año, la Asamblea General de la ONU encargó a la $\mathrm{CDl}$, estudiar la posibilidad de crear una corte penal internacional permanente. Sin embargo, la estructura bipolar del sistema internacional impidió que esta iniciativa tuviera éxito. Tanto la Unión Soviética, los países comunistas, los Estados Unidos y Gran Bretaña, se opusieron frontalmente a la creación de un tribunal de este estilo. Durante la Guerra Fría, se planteó como alternativa la extensión de la jurisdicción nacional de los Estados, facilitándoles el castigo de los crímenes internacionales, otorgándoles lo que se

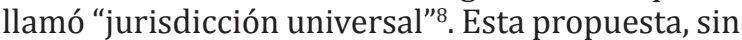
embargo, no era una alternativa a la creación de un tribunal penal permanente, sino más bien un complemento, pues en todo caso, el problema de juzgar a los violadores de los derechos humanos, no se debe a la carencia de herramientas jurídicas de los Estados, sino a la falta de voluntad política para condenar a los criminales. Es esta falta de voluntad lo que se pretendía corregir al crear una Corte Penal Internacional Permanente. La ausencia de herramientas jurídicas en las legislaciones internas de los Estados, es sólo una manifestación de la falta de voluntad de los Estados para juzgar a estos criminales.

En 1952, por la desconfianza recíproca entre los distintos bloques de poder durante la Guerra

7 Ver en El Tiempo, Suplemento Time Vol. 1 No. 20, de agosto 7 de 1998, pp. 12-13.

8 Graefrath, Bernhard, "Universal Criminal Jurisdiction and an International Criminal Court", en European Journal of International haw 67,1990, p. 73, citado por Steiner y Alston, op. cit., p. 1079
Fría, la definición del "delito de agresión" fue excluida del mandato que había recibido la CDI para crear el proyecto de Código de Crímenes contra la Humanidad y encargar a otra comisión. También fue delegado, a otra comisión, el proyecto de estatuto para la implementación de la CPI. Las nuevas comisiones estaban conformadas por representantes gubernamentales $y$, por lo tanto, carecieron de la independencia y determinación necesarias para llevar a cabo los proyectos encomendados. Si bien la Comisión de Representantes Gubernamentales, a la que se le encargó crear el proyecto de estatuto de la CPI, terminó sus labores con relativa rapidez, la que había sido creada con el propósito de definir el crimen de agresión no lo hizo sino 20 años más tarde. Esto llevó a que el proyecto de crear una corte penal internacional fuera olvidado.

No fue sino hasta 1989, curiosamente durante una conferencia especial de la Asamblea General sobre tráfico internacional de drogas, cuando se volvió a tratar el tema, acogido principalmente por países de Latinoamérica y el Caribe, los cuales formularon la iniciativa de crear una corte que condenara a los principales narcotraficantes del mundo.

Aunque la iniciativa de crear una corte que juzgara a los narcotraficantes no tuvo acogida, sí reabrió el camino para la discusión sobre la CPI, la cual, tras el establecimiento de los Tribunales ad hoc para Rwanda y Yugoslavia, llevó a que se acogiera favorablemente el proyecto de estatuto presentado a la Asamblea General por la CDI en 1994. La propuesta de la CDI continuó siendo trabajada por dos comités diferentes, el Comité preparatorio y el Comité ad hoc, que trabajaron hasta llegar al texto consolidado que fue presentado a la Conferencia Internacional de Plenipotenciarios en Roma, el 15 de junio de 1998.

\section{Organización}

La Corte está compuesta de cuatro (4) órganos, dos (2) oficinas semiautónomas y el Fondo para las Víctimas (The Trust Fund for Victims TFV). Los órganos son: Presidencia, Divisiones Judiciales, Oficina del Fiscal y Registro.

Las oficinas semiautónomas son la Oficina del Abogado Público para Víctimas y la Oficina del Abogado Público para la Defensa. 


\section{Asamblea de los Estados Partes}

La Asamblea de los Estados Partes es el órgano legislativo de la Corte Penal Internacional y está encargada de supervisar su gestión. Está compuesto por representantes de los Estados que han ratificado y adherido al Estatuto de Roma. Por principio de independencia de la Corte, y para garantizar su imparcialidad política, la Asamblea de los Estados Partes no es un órgano de la CPI. La ASP funciona en vez como el brazo legislativo de la Corte que igualmente garantiza su financiamiento. Según la Corte Penal Internacional, en su página web, actualizada hasta 2012, 120 países han firmado el Estatuto De Roma de la Corte Criminal Internacional, quedando dividido por zonas geográficas, así: países africanos, países asiáticos, Europa del Este, Latinoamérica y el Caribe y Europa del Oeste y otros países.

Una de las ideas que dirigió aquella asamblea era la de convertir a la Corte en un organismo realmente internacional. Pese a las críticas que suscitaron en su momento las reglas de ratificación que no permiten reservas, se estableció un alto número de quórum para que ésta entrara en funciones (60 ratificaciones). Las ratificaciones fueron logradas en cuatro años, entrando en vigor el Estatuto el 1 de julio de 2002.

\section{METODOLOGÍA}

Este estudios se realizó bajo la forma de investigación aplicada, teniendo en cuenta los objetos particulares de las investigaciones sociojurídicas, esta investigación tiene una relación directa con dichos objetos, los cuales permiten examinar detalladamente la situación problema planteada con la norma y la sociedad. Es un tipo de investigación correlacional que tiene como propósito medir el grado de relación y preponderancia que existe entre la soberanía del Estado Colombiano y la fuerza vinculante de ser parte del Estatuto de Roma. Se usó el método teórico de análisis y síntesis, considerando el objeto de nuestra investigación, éste método resultó ser el más idóneo y adecuado para conducirnos a los conocimientos requeridos y a las respuestas necesarias.

A través de éste método se afrontó la problemática y realizando una descomposición de las partes que conforman su estructura, de tal manera que nos permitió delimitar lo esencial, obtener nuevos conocimientos, hacer un análisis multifacético, y reducir lo complejo a lo simple. Para posteriormente formar una unidad conformada por todos los aspectos relevantes analizados. Se usaron fuentes secundarias que proporcionaron una variedad de información e interpretaciones, útiles en forjar nuestra propia postura frente a la problemática investigada.

\section{DESARROLLO DEL TEMA}

\section{DEL CONFLICTO}

\subsection{Contexto histórico}

El conflicto armado colombiano, es interno; se desarrolla en Colombia desde principios de la década de 1960. Los principales actores involucrados han sido el Estado colombiano y las guerrillas de extrema izquierda; a partir de la década de 1980, aparecen los grupos paramilitares de extrema derecha. Ha pasado por varias etapas de recrudecimiento, en especial desde los años ochenta cuando algunos de los actores se comenzaron a financiar con el narcotráfico. El conflicto tiene sus antecedentes históricos en la "época de la Violencia" (conflicto bipartidista de la década de 1950 y de años anteriores y que tiene sus orígenes primigenios cuando Colombia -entonces llamada la Nueva Granada- se independizó de España e inicia una pugna sobre el modelo de Estado que debía adoptar el país).

Durante la década de 1980, el conflicto armado presenta un rápido escalamiento que se caracteriza por la intimación generalizada que produce la guerrilla en numerosas regiones del país ${ }^{9}$, por los asesinatos selectivos de miembros civiles de la izquierda a manos de los nacientes grupos paramilitares, así como por la aparición de sectores del narcotráfico que chocan con la guerrilla en desarrollo de sus actividades delincuenciales (en particular, por el secuestro extorsivo de familiares de capos del narcotráfico por parte de la guerrilla). La época en la que se ubica el mayor recrudecimiento ocurrió entre

9 «Hablan las Farc». Semana.com (7 de agosto de 1987). Consultado el 8 de abril de 2013; "Historia de nunca acabar». Semana.com (18 de abril de 1988). Consultado el 8 de abril de 2013. 
1988 y $2003^{10}$, pero es en la segunda mitad de la década de 1990 cuando se presenta la mayor degradación del conflicto, debido a que se generalizan las tomas armadas de poblaciones, las desapariciones forzadas, las masacres indiscriminadas de civiles, el desplazamiento forzado masivo y los secuestros colectivos de civiles, militares y políticos, como tácticas de guerra $^{11}$; el pico de este recrudecimiento se presenta durante la presidencia de Andrés Pastrana y el inicio del gobierno de Álvaro Uribe, cuando confluyen el accionar del Estado, las guerrillas, grupos de narcotraficantes y paramilitares.

A partir de la desmovilización de los grupos paramilitares, que se lleva a cabo entre 2003 y 2006, sumado al debilitamiento de la guerrilla ${ }^{12}$, se presenta un descenso de la intensidad del conflicto. No obstante, las estructuras paramilitares no cesaron su accionar sino que empiezan a comportarse como carteles de droga con gran capacidad militar (llamados ahora Bacrim), mientras que la guerrilla todavía conserva capacidad de acción y confrontación, en ciertos lugares del país. En 2013 un estudio cifró en 220.000, las muertes causadas por el conflicto, desde $1958 .{ }^{13}$

\subsection{Causas}

Las causas para que se desarrollara el conflicto armado colombiano se centran en la pobreza, la falta de educación, el abandono estatal, las deficiencias socio-económicas en los núcleos familiares, y la pérdida de valores de la sociedad.

10 Restrepo, Jorge Alberto (3 de septiembre de 2004). «La dinámica del conflicto colombiano, 1998-2003». Semana.com. Consultado el 8 de abril de 2013.

11 Mejía Upegui, Juan Esteban (31 de enero de 2007). «Un vistazo a los años en los que el paramilitarismo inundó de sangre a Antioquia». Semana.com. Consultado el 8 de abril de 2013; «Un país que huye». Semana.com (22 de diciembre de 2002). Consultado el 8 de abril de 2013.

12 «El descontrol de las Farc». Semana.com (27 de octubre de 2008). Consultado el 8 de abril de 2013.

13 "El grupo de Memoria Histórica calcula que la cifra de desaparecidos llega a 25.000, algo que rebasa los crímenes de las dictaduras del Cono Sur. Además, hay un saldo de 6.000 niños reclutados, 10.000 personas amputadas por las minas antipersona y casi cinco millones de desplazados". "El conflicto armado en Colombia deja 220.000 muertos desde 1958" (EN LINEA) El País Internacional, publicado el 24 de julio de 2013. Consultado el 9 de septiembre de 2013. Ver en: http://internacional.elpais.com/internacional/2013/07/24/ actualidad/1374677621_928074.html
Es clara, además, la activa participación de menores en el conflicto.

La Comisión de Estudios sobre la violencia, creada por el gobierno de Belisario Betancourt, en 1987, a cargo del Instituto de Estudios Políticos y Relaciones Internacionales (IEPRI) de la Universidad Nacional de Colombia, realizó un estudio sobre las causas del conflicto. El estudio indicaba que la violencia política, tomada como una herramienta para lograr el acceso al control del Estado, no afecta los indicadores de violencia de una forma significativa, pues sólo constituía un 7,5 por ciento de los homicidios en 1985. Lo que realmente afecta, en forma considerable, los indicadores de violencia, son hechos como las riñas, las venganzas personales, la violencia intrafamiliar y el sicariato, principalmente ${ }^{14}$.

Otra causa, radica en la concentración o monopolización del campo por terratenientes y el desplazamiento de campesinos hacia los centros urbanos que, en ocasiones, generaba resistencia. El llamado gamonalismo, heredado de los colonizadores españoles por, las élites criollas que luego se tomaron el poder político y económico del estado, y que, más tarde, evolucionó al "Terrorismo de Estado".

Con el boom del narcotráfico hacia Estados Unidos y Europa en las décadas de 1970 y 1980, los campesinos se dedicaron a la plantación de cultivos ilícitos, financiados inicialmente por narcotraficantes. El narcotráfico, fuente de dinero fácil, generó corrupción, constituyendo redes que comprometieron a todos los actores presentes en el conflicto armado colombiano, mientras que Estados Unidos declaraba la Guerra contra las drogas. Muchos de esos movimientos campesinos se consolidaron en movimientos de campesinos cocaleros, que sentaron las bases de las guerrillas como las FARC, similar a lo ocurrido en Perú y Bolivia ${ }^{15}$. El narcotráfico degeneró los ideales iniciales y creó una nueva economía que se mantiene como el principal combustible del conflicto.

14 Venganza y cultura en Bogotá: Arturo Laguado. Escuela de Ciencias Humanas - Universidad del Rosario.

15 Comisión de la Verdad (Perú): NARCOTRÁFICO, CONFLICTO ARMADO INTERNO Y CORRUPCIÓN. 


\subsection{Efectos}

El conflicto armado colombiano ha generado miles de muertos, lisiados, secuestrados, una de las peores crisis de desplazamiento forzado en el mundo y desaparecidos, lo que ha conllevado a que Colombia se le clasifique como uno de los países más violentos del mundo y uno de los principales exportadores de drogas ilegales ${ }^{16}$.

La década de 1970 a 1980 se caracterizó por una desmedida represión por parte del Estado (Ejército, Policía y autoridades civiles) contra los movimientos políticos, obreros, campesinos y estudiantiles. Además, algunos particulares tomaron con su propia mano la aplicación de medidas represivas contra los mencionados sectores. Según el Centro de Investigación y Educación Popular (CINEP) entre el 1 de enero de 1970 y el primer trimestre de 1981, ocurrieron numerosos asesinatos, torturas, desapariciones y otras violaciones de los Derechos Humanos. "Desde 1970 hasta marzo de 1981 se presentaron 1.053 asesinatos y 7.571 casos de torturas provocados principalmente por las Fuerzas Armadas"17.

\section{a) Muertes}

Según la ONG Amnistía Internacional, entre 2006 y 2008, los casos de las personas y comunidades que han sido golpeadas con mayor dureza por el conflicto, son miembros de comunidades indígenas, afro-descendientes $\mathrm{y}$ campesinas que han sido víctimas de homicidio o de desplazamiento forzado. En 2007, hubo alrededor de 1.400 homicidios de civiles, superior a los 1.300 que se dieron en 2006. En los casos en los que se logró identificar a los autores, las fuerzas estatales fueron responsables de al menos 330 , los grupos paramilitares de unos 300 y los grupos guerrilleros de alrededor de $260^{18}$.

16 «Colombia sigue siendo el mayor exportador mundial de cocaína» (en español). El Universal (Venezuela) - El Tiempo (Colombia). Consultado el 01/07/2008; «Colombia, el país más violento de América Latina» (en español). El Tiempo (Colombia). Consultado el 26/05/2008.

17 Jaime Torres Sánchez, Luz Amanda Salazar Hurtado: Introducción a la historia de la Ingeniería y de la educación en Colombia. Versión OnLine.

18 Amnesty International: Más muertes y abusos mientras el gobierno colombiano niega la situación de derechos humanos.

\section{b) Lisiados y discapacitados}

Se calcula que en Colombia hay sembradas unas 100 mil minas antipersonal, donde las principales víctimas son los civiles que han contribuido a aumentar las cifras de muertos o lisiados ${ }^{19}$

\section{c) Reclutamiento forzado}

De acuerdo a reportes del Comité para los Refugiados de Naciones Unidas, en el 2008 se presentaron hechos de reclutamiento forzado de menores de edad por partes de las fuerzas del Estado para recopilar información de inteligencia sobre los grupos armados ilegales. Según el mismo organismo, las guerrillas de las FARC y el ELN, además de grupos paramilitares no desmovilizados, practicaron, en gran escala, el reclutamiento forzado de niños campesinos para la guerra como una contribución de las familias para enfrentar a las fuerzas armadas del Estado; este reclutamiento se ha extendido e incrementado en las regiones fronterizas con Venezuela y Ecuador.

\section{d) Desplazamiento forzado}

Colombia es el país con mayor cantidad de desplazados en el mundo. Cerca de 4,9 y 5,9 de personas han sido desplazadas a causa del conflicto armado, según la más reciente cifra publicada en 2012 por el Centro de Monitorio del Desplazamiento Interno ${ }^{20}$. El informe no incluye a personas desplazadas por el narcotráfico o las bandas criminales.

Colombia es uno de los países del mundo con el mayor número de desplazados internos. Hasta mayo de 2011 el Gobierno de Colombia ha registrado a más de 3,7 millones de desplazados internos en el país. ONG como la Consultoría para los Derechos Humanos y el Desplazamiento (CODHES) consideran que la cifra real de desplazados por el conflicto armado interno desde mediados de los años 80 supera los 5 millones de personas $^{21}$.

19 Unicef: Sembrando Minas, Cosechando Muertes.

20 Herrera Durán, Natalia (29 de abril de 2013). «Colombia, el país con más desplazados en el mundo». El Espectador Consultado el 30 de abril de 2013.

21 «Desplazamiento interno en Colombia». ACNUR. Consultado el 05-03-2013. 
El desplazamiento en el país es una causa directa del conflicto armado de Colombia. Con casi 400.000 refugiados y entre 4,9 y 5,9 millones de desplazados internos en 2012, el país es protagonista del mayor drama humanitario de América Latina, según el Alto Comisionado de las Naciones Unidas para los Refugiados (ACNUR).

\section{e) Narcotráfico}

Colombia tuvo cuatro de los carteles de narcotráfico más poderosos del mundo, que en algunos casos crearon una nueva clase social e influenciaron notablemente la cultura colombiana. En la actualidad, el cartel del narcotráfico mejor consolidado en Colombia lo conforman las FARC; de las 350 toneladas de cocaína que anualmente se producen y se trafican en Colombia, 200 corresponden a las FARC, que le producen más de 3.500 millones de dólares anuales de ganancias para financiar la guerra ${ }^{22}$; le siguen, en su orden, el ELN y las Bacrim. El narcotráfico ha tenido directa influencia en la guerra y en la vida política, social y económica del país. Varios dirigentes nacionales han sido acusados de alianzas con grupos de narcotraficantes y/o grupos armados ligados al narcotráfico para ganar poder político y económico.

El uso de la hoja de coca, la marihuana y otras plantas, había sido parte del estilo de vida de algunas comunidades indígenas a lo largo de América del Sur, pero la demanda mundial de drogas psicoactivas durante las décadas de 1960 y 1970 incrementaron la producción y procesamiento de estas en Colombia. Se implementaron leyes de prohibición en Estados Unidos y en Colombia para sofocar el efecto negativo de las drogas en la sociedad y castigar a quienes las cultivaran, poseyeran, comercializaran o distribuyeran.

Desde el establecimiento de la guerra contra las drogas, los Estados Unidos y algunos países europeos han proveído al gobierno colombiano ayuda logística y financiera para implementar planes que permitan combatir el tráfico de drogas. El programa más notable ha sido el polémico Plan Colombia, el cual también está destinado a

22 Juan Carlos Pinzón, Ministro de Defensa Nacional de Colombia (24 de octubre de 2012). "Las FARC obtienen hasta 3.500 millones de dólares anuales del narcotráfico". Agencia de noticias RIANOVOSTI. Consultado el 25 de Octubre de 2013 en Internet: http://sp.ria.ru/international/20121024/155357762.html combatir los grupos armados ilegales calificados por estos países como terroristas, entre ellos paramilitares y guerrillas, que en la década de 1980 empezaron a financiarse con esta actividad ilícita.

A pesar de estos programas, Colombia continuó siendo el líder mundial en producción de cocaína con aproximadamente el $70 \%$ del total de distribución a nivel mundial y el $90 \%$ del procesamiento, según un informe del Departamento de Estado de los Estados Unidos en 2004.

En 2012 un informe del Departamento de Estado de los Estados Unidos aseguró que Perú y Bolivia habían superado a Colombia como principales productores de cocaína.

\section{f) Medio ambiente}

El gobierno y el sector industrial de Colombia han abogado e implementado monocultivos de plantas que generan daño a la fertilidad de los suelos, como el caso de la palma africana para la generación de biocombustibles. La principal implicación ambiental, de algunos monocultivos, es el deterioro acelerado de los suelos; además, el uso intensivo de agroquímicos, implica daños al medio ambiente, especialmente en regiones selváticas. Los cultivos de palma africana en regiones selváticas del Pacífico colombiano, deterioran los suelos en uno de los lugares con mayor biodiversidad en el mundo. El gobierno busca abrir paso al desarrollo capitalista y, además, disminuye las selvas que dan ventaja táctica a las guerrillas y demás grupos ilegales.

Los grupos guerrilleros como las FARC y el ELN, adoptaron políticas de destrucción de la infraestructura económica que sirve al gobierno y a los intereses de multinacionales capitalistas. Desde 1984, la destrucción de oleoductos petroleros es la táctica que más han utilizado las guerrillas y han afectado el medio ambiente. Dichos derrames de petróleo han causado la contaminación de suelos, fauna y flora, e importantes cuencas hidrográficas ${ }^{23}$.

23 Fuerzas Aérea Colombiana: Junio 5 de 2004 / Día Mundial del Medio Ambiente: El desastre ecológico causado por el terrorismo en Colombia. 
Los grupos armados ilegales envueltos en el negocio del narcotráfico como las FARC, ELN y BACRIM han promovido su expansión, con la generación de demanda, lo que genera mayor destrucción de selva o bosque virgen para dar paso al cultivo ilícito.

\section{g) Respuesta popular}

A lo largo del conflicto armado colombiano, se han producido protestas populares contra los hechos violentos causados por los diferentes actores del conflicto armado, especialmente contra las FARC. Los más importantes han sido el Movimiento de la "Séptima papeleta" que, en parte, se le atribuyó el impulso para la creación de la Constitución de Colombia de 1991. A principios del siglo XXI se llevaron a cabo Homenajes a las víctimas del paramilitarismo, de la para-política y los crímenes de Estado. La protesta de un millón de voces contra las FARC, dejó al descubierto el rechazo del pueblo colombiano contra esta organización armada ilegal; igual sensación causó el Gran Concierto por la Paz del 20 de julio de 2008.

\section{h) Imagen internacional de Colombia}

En países que presentan fenómenos de mafias y narcotraficantes, dicho fenómeno se comenzó a denominar "colombianización", donde hacen convergencia el narcotráfico, la violencia y la corrupción. El término ha sido utilizado por la prensa de países como España, Guatemala, México, Venezuela, Nicaragua y Ecuador. A Colombia se le ha asociado incluso con Afganistán por la asociación entre mafias, terroristas y narcotráfico.

\section{DEL PROCESO DE PAZ EN COLOMBIA}

Los procesos de paz en Colombia, se resumen en conversaciones y diálogos de paz entre el gobierno nacional y los grupos revolucionarios con miras a acabar el conflicto armado en el país. El primer proceso de paz comienza desde la presidencia de Belisario Betancur con los acercamientos con grupos insurgentes, llevando a que la guerrilla del M-19 se desmovilizara en 1989. Luego se reanudó en la presidencia de Andrés Pastrana (1998 - 2002), donde el gobierno adelantó diálogos de paz con las FARC en San Vicente del Caguán, durante la fallida zona de despeje. En la presidencia de JUAN MANUEL
SANTOS (2010 - 2014), se reinicia con las FARC el proceso de paz en Colombia.

\subsection{Cronología de los procesos de paz en Colombia: Tres décadas de intentos. El mayor éxito lo tuvo el gobierno de VirgilioBarco, con el M-19}

Una gran ilusión generó en millones de colombianos el anuncio del presidente Juan Manuel Santos, acerca del inicio de los diálogos de paz con las FARC. Sus antecedentes fueron:

1981: El Gobierno del presidente liberal Julio César Turbay Ayala creó una comisión de paz para iniciar conversaciones con la guerrilla. El político Carlos Lleras Restrepo, quien tenía la misión de liderar el proceso, renunció con el argumento de que no lo dejaron establecer contactos con la insurgencia.

1982: El entonces presidente conservador Belisario Betancur Cuartas inició una negociación de paz con las Fuerzas Armadas Revolucionarias de Colombia - FARC.

1984: El Gobierno de Betancur y las FARC firmaron el Acuerdo de La Uribe, que incluyó el cese bilateral del fuego, la suspensión del secuestro y la apertura de espacios políticos para la guerrilla. El proceso fracasó y se rompió en 1987.

1988: El presidente liberal Virgilio Barco Vargas comenzó un acercamientos de paz con las FARC, pero el exterminio a manos de paramilitares de ultraderecha de miles de militantes del partido izquierdista Unión Patriótica, vinculados con esa guerrilla, impidió avanzar. Barco también inició diálogos con la guerrilla del M-19 y expidió una ley de amnistía.

1990: El Gobierno de Barco firmó un acuerdo de paz con el M-19, que entregó las armas, se reintegró a la vida civil y se convirtió en una fuerza política que, en la actualidad, gobierna, entre otros, a Bogotá, la capital de la República de Colombia entre otras.

1991: El entonces presidente César Gaviria inició conversaciones con las FARC y el Ejército de Liberación Nacional (ELN) en Caracas, capital 
de Venezuela y luego se trasladaron a Tlaxcala, en México.

En 1992 se rompió el proceso por el asesinato de un ex ministro secuestrado por la guerrilla. En ese mismo año, se desmovilizaron las guerrillas del Ejército Popular de Liberación (EPL), el grupo indigenista Quintín Lame y el Partido Revolucionario de los Trabajadores (PRT) después de acuerdos de paz.

1993: Durante el Gobierno de Gaviria se reintegraron a la vida civil y entregaron las armas los integrantes de la Corriente de Renovación Socialista, una disidencia del ELN.

1998: El Gobierno del presidente Ernesto Samper concedió el estatus político al ELN en un esfuerzo por lograr un acuerdo de paz. También hubo encuentros con ese grupo rebelde en España y Alemania que no prosperaron.

Ese mismo año, el entonces candidato conservador Andrés Pastrana ganó la presidencia de Colombia con la promesa de iniciar un diálogo de paz con las FARC para poner fin al conflicto interno.

Siendo mandatario, retiró las Fuerzas Militares y la Policía de una zona comprendida por los municipios de Mesetas, La Uribe, La Macarena, Villahermosa y San Vicente del Caguán, con una dimensión de 47 mil kilómetros cuadrados para que sirviera de sede a la negociación.

1999: Se inició el proceso con las FARC, el tercer intento formal para lograr la paz con esa guerrilla. Los diálogos se realizaron en medio de la confrontación y se rompieron en febrero del 2002. Durante el Gobierno de Pastrana, también se mantuvieron aproximaciones con el ELN, sin lograr avances concretos.

2002: Durante el Gobierno del presidente Álvaro Uribe, quien lanzó una ofensiva militar contra la guerrilla con el apoyo de Estados Unidos, se inician diálogos con el ELN en Cuba. Entre el 2004 y el 2005 hubo facilitación de México y en el 2007 se intentó restablecer el proceso con ese grupo rebelde en Venezuela con la mediación del presidente Hugo Chávez, pero una vez más las aproximaciones fracasaron.
2012: El presidente Juan Manuel Santos anunció que su Gobierno y las FARC firmaron un acuerdo marco que establece un procedimiento $y$ una hoja de ruta, para avanzar en negociaciones de paz que comenzaron en la primera quincena de octubre en Oslo, Noruega, y luego continuaron en La Habana, Cuba.

El máximo comandante de las FARC, Rodrigo Londoño, alias "Timoleón Jiménez" o 'Timochenko', se declaró optimista sobre el proceso de negociación. No obstante, el pueblo colombiano ha sido muy escéptico; el bajo nivel de aceptación que el proceso ha tenido, queda demostrado a través de diferentes encuestas publicadas en los medios de comunicación del país.

\section{DE LA CORTE PENAL INTERNACIONAL}

\subsection{Funcionamiento}

La Corte funciona como un organismo autónomo de cualquier otro poder o Estado. Sin embargo, esto no obsta para que, en el cumplimiento de su deber, cuente con la colaboración de los Estados.

\subsection{Crímenes}

Los crímenes que puede conocer la Corte se encuentran limitados a los señalados en el artículo 5 del Estatuto de Roma, son: El genocidio (art. 6); los crímenes de lesa humanidad (art. 7); los crímenes de guerra (art. 8); y el Crimen de agresión (art. 8 bis, según Resolución 6 del 11/06/2010 de la Asamblea de Estados Parte del Estatuto de Roma).

\subsection{Investigación y enjuiciamiento}

La investigación de los hechos que fueran constitutivos de delitos se puede iniciar por tres formas (art. 13): Por remisión de un Estado Parte a la Corte, en una situación particular; por solicitud del Consejo de Seguridad de las Naciones Unidas (donde se aplica el veto invertido) o de oficio, por el Fiscal de la Corte.

Una vez que el Fiscal de la Corte maneje estos antecedentes, puede: o archivarlos o presentar una acusación, que es revisada por la Cámara de Asuntos Preliminares. Si es procedente, se 
acoge la acusación que pasa a ser conocida por la Cámara de Primera Instancia, donde se realiza el juicio. Una vez absuelto o condenado, tanto el Fiscal como el condenado en su caso, pueden apelar o casar ante la Cámara de Apelaciones.

\subsection{Penas y cumplimiento}

Las penas que puede establecer la sentencia puede ser de prisión por un plazo no mayor de 30 años, o (por la gravedad de los crímenes) cadena perpetua, además de una multa y el decomiso de las especies que sean de propiedad del condenado (art. 77). La pena se puede llevar a cabo en el país sede de la Corte (Holanda) o en otro, de acuerdo con los convenios que se puedan establecer entre la Corte y otros países.

\subsection{Relación con los Estados y Organismos Internacionales}

La Corte, en virtud de las normas del Estatuto que la autorizan, podrá pactar con diferentes Estados diversas formas de cooperación, de investigación o de cumplimiento de condenas. Estos pactos suelen ser considerados complementarios al Estatuto para quienes los firman. A modo de ejemplo, el año 2005, Austria firmó un acuerdo de cooperación y de apoyo a las investigaciones que realice la Corte.

En cuanto a las Naciones Unidas, el Estatuto en su artículo 2 señala que: "la Corte estará vinculada con las Naciones Unidas por un acuerdo que deberá aprobar la Asamblea de los Estados Partes en el presente Estatuto y concluir luego el Presidente de la Corte en nombre de ésta". En este sentido, es importante destacar la situación del "veto invertido", establecido en el Estatuto. Esta modificación cambia el efecto que tiene la aplicación por alguno de los países que cuentan con un asiento permanente en el Consejo de Seguridad, de su derecho a veto. Esto se traduce en que al momento de utilizar este derecho, sólo tendrá el efecto de evitar que el Consejo haga aplicación del derecho que tiene a solicitar a la Corte la no iniciación o suspensión de una investigación en curso ante la Corte.

\section{LA PAZ Y LA JUSTICIA ¿DOS VALORES ENFRENTADOS?}

En la historia de las diversas cortes penales, así como en los procesos de reconciliación nacional, ha estado siempre presente el dilema entre justicia y paz.

Al respecto, hay quienes sostienen que se debe sacrificar la justicia para poder alcanzar la paz. Algunos de ellos argumentan que debido a la dinámica de los conflictos bélicos, para que sea posible la reconciliación entre las partes, se deben resolver, antes que nada, los motivos que le dieron origen, aun cuando esto implique impunidad. Otros, dentro de la misma línea, aun cuando más radicalmente, afirman que la única forma en que la justicia es efectiva, es cuando se ha obtenido la paz derrotando militarmente a quienes se pretende condenar. José Zalaquett, quien hizo parte del movimiento de derechos humanos en Chile, dice que se siente conforme con el resultado del proceso chileno, satisfecho con las medidas sumamente prudentes que tomó el presidente Aylwin ${ }^{24}$. James Crawford, por su parte, refiriéndose al caso de Yugoslavia, anota que el establecimiento de tribunales penales internacionales ad hoc puede desviar la atención de los conflictos en sí, si se centra en el castigo de los criminales ${ }^{25}$. Kenneth Anderson, también, con un criterio eminentemente "clásico" de las relaciones internacionales, adujo que la implementación de un tribunal internacional ad hoc en Yugoslavia, al no ser impuesto por los victoriosos a los vencidos, no es más que un despropósito, pues primero debe solucionarse el conflicto bélico y después juzgar a los criminales, descartando con ello, la función pacificadora de los tribunales penales internacionales ${ }^{26}$.

En sentido contrario, se puede afirmar que la necesidad de asegurar la paz, puede, en ciertos casos, implicar una "economía" en términos de la condena a los criminales, que produzca una sensación de inconformidad con respecto al proceso de paz. Esto le restaría legitimidad al mismo, e impediría obtener los resultados esperados. Sin embargo, la relación entre justicia y paz no siempre es dilemática. El problema radica

24 Zalaquett, José, "Balancmg Ethical Imperatives and Political Constraints: The Dilemma of New Democracies confronting Past Human Rights Violations", en Hastings Law Journal 1425,1992, íbídem, pp. 1106-1108.

25 Crawford, James, "The ILC Adopts a Statute for an International Criminal Court", en American Journal of International Law 404,1995, p. 408, íbídem, p. 1084.

26 Anderson, Kenneth, "Nuremberg Sensibility: Telford Taylors Memoir of the Nuremberg Iríais", 7 Harvard Human Rights Journal 281 (1994). 
en saber escoger los criterios para determinar cuál es el punto de equilibrio entre estos dos fines $\mathrm{y}$, en últimas, en establecer un consenso respecto de lo que significa la "paz social".

Para entender la verdadera dinámica entre la paz y la justicia, se debe tener en cuenta que no son necesariamente polos opuestos. Para esto, debe dejarse de lado la concepción de la justicia como la mera imposición de sanciones penales a los criminales internacionales, pues no son solamente las funciones disuasiva y preventiva de la pena las que contribuyen a la obtención de la paz social. En otras palabras, no es sólo el temor a ser castigado penalmente lo que disuade a las personas de cometer crímenes, ni encerrando a todos los criminales se evita la criminalidad.

El conocimiento de la verdad de los hechos por parte de la comunidad, en general, y la condena pública a los culpables, son, de por sí, factores fundamentales en la obtención de la paz, pues contribuyen a generar una conciencia pública sobre lo sucedido. Ésta parece ser una rationale (razón de justicia) aceptada, al menos parcialmente, hoy en día por el Derecho internacional. Hay varios indicios que parecen mostrar que los Estados tienen la obligación internacional de sancionar a quienes cometan cierto tipo de violaciones contra los derechos humanos y que, por lo tanto, las leyes generales de amnistía otorgadas por los Estados son consideradas contrarias al Derecho Internacional de los Derechos Humanos. Si bien es atrevido determinar que existe una costumbre internacional general que proscriba las amnistías respecto de cualquier violación a los derechos humanos, sí hay algunas violaciones sobre las cuales se han manifestado diversos organismos internacionales.

\section{EL PROCESO DE PAZ COLOMBIANO Y LA CORTE PENAL INTERNACIONAL}

En Colombia, la tensión entre la paz y la justicia parece ser un punto bastante sensible. En tal medida, conviene que la sociedad civil, fije unos mínimos consensos respecto del proceso en sí. Adicionalmente, el gobierno debe ser permeable a lo que allí suceda, con el objeto de conducir el proceso de paz y administrar la justicia de la mejor manera posible. Para ello, conviene reflexionar sobre algunas de las cuestiones que se presentan a continuación.
En gran parte de los intentos de sancionar a los violadores de los Derechos Humanos, los Estados han atravesado etapas de transición de un régimen dictatorial o militarista, a uno democrático. Aunque en distinto grado, la inestabilidad política de estos períodos, debilita la voluntad de los gobiernos entrantes para llevar a cabo procesos de condena a los violadores de los derechos humanos. En estas situaciones, además de estar limitada la capacidad de los gobiernos para llevar a cabo juicios internamente, de acuerdo con sus sistemas judiciales nacionales, la intervención de la comunidad internacional parece ser ineficaz. Los organismos internacionales y los terceros Estados que participan en el restablecimiento de los gobiernos democráticos también se muestran reacios a condenar los casos particulares de violación de los derechos humanos, cuando consideran que se puede perjudicar la paz y la seguridad.

En Colombia, éste no es el caso. El proceso de paz no corresponde al restablecimiento de un orden democrático, ni la violación de los derechos humanos (especialmente el Derecho Internacional Humanitario) ha sido perpetrada exclusivamente por uno de los actores en conflicto. Sin embargo, el Estado colombiano sí tiene unas insuficiencias institucionales que disminuyen los recursos de poder del gobierno para controlar los problemas de violencia causados por los diversos grupos armados dentro de su territorio. Muestra de ello es la incapacidad del gobierno para sancionar las violaciones a los derechos humanos, excepto al interior de sus propias Fuerzas Armadas.

Durante un proceso de paz negociado, la escasez de los recursos de poder del Estado se hace aún más evidente. Los compromisos que adquiere el gobierno de restringir aún más su capacidad de acción (ya de por sí bastante limitada), sumado al creciente poder que adquieren los diversos grupos armados, limitan considerablemente la voluntad política del gobierno para llevar a cabo juicios imparciales a los violadores de derechos humanos. En esta situación, cualquier iniciativa de investigar la comisión de estos delitos, por parte de las Fuerzas Armadas, las autodefensas o la guerrilla, implica un aumento del poder relativo de los demás grupos.

Esto significa que el gobierno tiene una mayor posibilidad y al mismo tiempo una mayor responsabilidad de llevar a cabo juicios imparciales 
a los violadores de los derechos humanos.

Sin embargo, paradójicamente, una investigación exhaustiva e imparcial de las violaciones de los derechos humanos durante el proceso de paz, le podría dar legitimidad al mismo. Esto es posible, en la medida en que si las investigaciones son llevadas a cabo de manera diáfana, por parte de un organismo con altos niveles de credibilidad a nivel nacional, las diversas partes en el conflicto pueden empezar a confiar en el proceso. En el caso colombiano, la condena a los violadores de los derechos humanos, no significa un ataque frontal a uno de los actores en el conflicto que pudiera hacerlo reaccionar, recrudeciendo el problema. Todos los actores dentro del conflicto han reconocido, de alguna u otra manera, que han incumplido las normas mínimas de respeto por los derechos humanos durante los conflictos armados internos. Las concesiones hechas por el ELN durante el Acuerdo de Mainz, los acuerdos del nudo de Paramillo y las cartas de las autodefensas, así como los reconocimientos públicos del ex presidente Samper, así lo demuestran. Esto, visto de manera optimista, puede ser interpretado como el comienzo de la formación de un consenso en cuanto a la necesidad de respetar el Derecho Internacional Humanitario.

Resulta bastante representativo de la situación colombiana que el Estado y la Comunidad de Derechos Humanos ${ }^{27}$ coincidan en que, antes de cualquier acuerdo de paz, sea con los grupos guerrilleros o con las autodefensas, todas las partes deben comprometerse a respetar las normas mínimas de los derechos humanos aplicables a los conflictos armados.

\section{CONCLUSIONES}

La importancia que tiene para el proceso de paz colombiano llevar a cabo investigaciones imparciales de las violaciones de derechos humanos es fundamental. La importancia de la imparcialidad es una consecuencia de la tendencia humana a considerar la justicia (como reciprocidad) como requisito previo a cualquier cooperación. En el campo de las ciencias sociales,

27 Este término corresponde no sólo a la comunidad de Derechos Humanos representada en Organismos No Gubernamentales. También corresponde a quienes individualmente desarrollan actividades tendientes a proteger los derechos humanos en Colombia. los motivos que impulsan a la cooperación han sido analizados experimentalmente. Es conveniente resaltar los resultados de algunos de estos experimentos.

En la teoría de juegos, los experimentos secuenciados del "Dilema del Prisionero", que se han hecho para estudiar el comportamiento de los Estados en las relaciones internacionales, muestran que la cooperación entre los jugadores sólo es posible cuando se cumplen dos condiciones. La primera de ellas, es que exista un sentimiento de reciprocidad, y la segunda, que los jugadores compartan el mismo concepto con respecto a los objetivos del juego.

Así, la necesidad de reciprocidad en el juego se evidenció, ya que después de una "traición", de una sucesión de varias traiciones por parte de un jugador, la cooperación sólo es posible cuando su contrincante obtiene "venganza". Del mismo modo, si se le concede una amnistía generalizada a la guerrilla, y se sanciona plenamente a las autodefensas, éstas no aceptarán el proceso de paz. Si, por el contrario, se castiga a los militares o policías por las violaciones al Derecho Internacional Humanitario, y se deja impune a los militantes de las FARC o el ELN, aquéllos considerarán que el gobierno o el Estado, ha sido injusto, pues ha castigado a las fuerzas legítimas del Estado y premiado a las ilegales.

De los resultados de tales experimentos, se ha concluido que los jugadores que coinciden en las definiciones del juego, interpretan las "traiciones" de sus contrincantes como parte de una secuencia más amplia de cooperación, en la cual, es necesario cierto nivel de equilibrio previo para poder cooperar. Dentro del desarrollo del juego éstos fueron los jugadores que obtuvieron mayores puntajes ${ }^{28}$. Teniendo en cuenta que en Colombia las partes en conflicto están comenzando a tener conciencia en cuanto a los mínimos que se deben respetar dentro del conflicto (así éstos no sean los mínimos fijados por el Derecho Internacional Humanitario), es conveniente aprovechar la coyuntura y empezar a crear un consenso mínimo en cuanto a un concepto de "paz social", en el cual se vayan fijando los criterios para establecer

28 Hurwitz, Roger; Strategic and Social Fictions in the Prisioners Dilemma, en Der Derian, James y Shapiro, Michael, International/ lntertextual Relations. Postmodern Readings of World Politics, Lexington Books, Lexington Massachusetts, 1989, pp. 113-134. 
un equilibrio entre la paz y la justicia. De lo contrario, si éstos son impuestos arbitrariamente, los diversos actores del conflicto se polarizarán, impidiendo que lleguen a un consenso político, respecto de la reforma institucional que desean.

De otra parte, teniendo en cuenta que Colombia ratificó el Estatuto de la Corte Penal Internacional, se comprometió a entregar -entre otras- a aquellas personas a quienes no pueda o no quiera juzgar, por los delitos contenidos en el Estatuto, cometidos en su territorio o por sus nacionales.

En conclusión, mientras el Derecho Internacional Penal mantenga en sus estatutos, que no es posible amnistía o indulto para crímenes como los de lesa humanidad o los crímenes de guerra, los márgenes de maniobra del gobierno colombiano en el proceso de paz son limitados, salvo que los miembros de las FARC estén dispuestos a recibir penas, así sean reducidas pero efectivas, por los múltiples crímenes cometidos contra el pueblo colombiano, a lo largo de la confrontación armada. Así lo ha ratificado la Corte Penal Internacional, cuando el Fiscal Fatou Bensouda, aseguró en una carta, que no admite la justicia transicional y que en caso de no ejecutarse penas efectivas contra los máximos responsables de delitos de lesa humanidad y otros, se estaría en contravía de los postulados de la Corte Penal Internacional. Últimamente, en el mismo sentido, lo ha expresado en Colombia el Fiscal General de la Nación, cuando afirmó: "El proceso de paz, no se pacta sobre la impunidad" 29

\section{BIBLIOGRAFÍA}

- Anderson, Kenneth, "Nuremberg Sensibility: Telford Taylors Memoir of the Nuremberg Iríais", 7 Harvard Human Rights Journal 281 (1994).

- Crawford, James, "The ILC Adopts a Statute for an International Criminal Court", en American Journal of International Law 404,1995.

- Dinstein, Yoram; International Criminal Law, en Israel Yearbook on Human Rights 5, p. 55, 1975, citado por Steiner, Henry y Alston, Philip (comps.); Human Rights in Context, Clarendon Press, Oxford, 1996.

- Graefrath, Bernhard, "Universal Criminal Jurisdiction and an International Criminal Court", en European Journal of International haw 67,1990.

- Hurwitz, Roger; Strategic and Social Fictions in the Prisioners Dilemma, en Der Derian,
James y Shapiro, Michael, International/ lntertextual Relations. Postmodern Readings of World Politics, Lexington Books, Lexington Massachusetts, 1989.

- Laguado Arturo, Venganza y cultura en Bogotá., Escuela de Ciencias Humanas Universidad del Rosario.

- Meron, Theodor; The Case for War Crimes Triáis in Yugoslavia, en Foreign Affairs 122, No. 3,1993.

- Torres Sánchez Jaime, Salazar Hurtado Luz Amanda: Introducción a la historia de la Ingeniería y de la educación en Colombia. Versión OnLine.

- Zalaquett, José, "Balancmg Ethical Imperatives and Political Constraints: The Dilemma of New Democracies confronting Past Human Rights Violations", en Hastings Law Journal 1425,1992. 


\section{Artículos}

- Amnesty International: Más muertes y abusos mientras el gobierno colombiano niega la situación de derechos humanos.

- «Colombia sigue siendo el mayor exportador mundial de cocaína» (en español). El Universal (Venezuela) El Tiempo (Colombia). Consultado el 01/07/2008; «Colombia, el país más violento de América Latina» (en español). El Tiempo (Colombia). Consultado el 26/05/2008.

- Comisión de la Verdad (Perú): NARCOTRÁFICO, CONFLICTO ARMADO INTERNO Y CORRUPCIÓN.

- «El descontrol de las Farc». Semana.com (27 de octubre de 2008). Consultado el 8 de abril de 2013.

- Fuerzas Aérea Colombiana: Junio 5 de 2004 / Día Mundial del Medio Ambiente: El desastre ecológico causado por el terrorismo en Colombia.

- «Hablan las Farc». Semana.com (7 de agosto de 1987). Consultado el 8 de abril de 2013; «Historia de nunca acabar». Semana.com (18 de abril de 1988). Consultado el 8 de abril de 2013.
- Herrera Durán, Natalia (29 de abril de 2013). «Colombia, el país con más desplazados en el mundo». El Espectador. Consultado el 30 de abril de 2013.

- Mejía Upegui, Juan Esteban (31 de enero de 2007). «Un vistazo a los años en los que el paramilitarismo inundó de sangre a Antioquia». Semana.com. Consultado el 8 de abril de 2013; «Un país que huye». Semana.com (22 de diciembre de 2002). Consultado el 8 de abril de 2013.

- Restrepo, Jorge Alberto (3 de septiembre de 2004). «La dinámica del conflicto colombiano, 1998-2003». Semana.com. Consultado el 8 de abril de 2013.

- Unicef: Sembrando Minas, Cosechando Muertes.

- El Tiempo, Suplemento Time Vol. 1 No. 20, de agosto 7 de 1998, pp. 12-13.

\section{Internet}

- ht tp: / / sp.ria.ru/internation al/20121024/155357762.html

- http://www.elespectador.com/noticias/ judicial/fiscal-rechaza-criticas-de-cortepenal-internacional-al-articulo-454163 